\title{
DAKWAH VISUAL: EKSPRESI KEIMANAN SEORANG MUSLIM DALAM BENTUK POSTER DIGITAL
}

\author{
Ahmad Faiz Muntazori \\ Mahasiswa Program Doktor Institut Seni Indonesia Surakarta \\ Dosen Program Studi Desain Komunikasi Visual Uninversitas Indraprasta PGRI
}

\begin{abstract}
Abstrak. Kesenian merupakan salah satu unsur kebudayaan yang mendapatkan perhatian khusus dalam masyarakat Islam. Praktik kesenian dalam perspektif agama yang berhubungan dengan gerakan moral, salah satunya tampak pada media dakwah visual. Tulisan ini bertujuan mengungkapkan makna poster dakwah, pesan apa yang ingin disampaikan oleh desainer kepada umat Islam secara luas. Selain itu, Tulisan ini juga ingin menemukan kaitan antara seni dan agama. Metode yang digunakan adalah metode kualitatif. Adapun semiotika Peirce digunakan sebagai alat analisis. Hasilnya, poster dakwah sebagai media untuk berdakwah merupakan salah satu ekspresi kecintaan kepada Sang Khalik. Poster dakwah merupakan sebentuk media persuasif yang mengingatkan tugas utama makhluk kepada Tuhannya, yaitu beribadah.
\end{abstract}

Kata Kunci: dakwah visual, poster dakwah, semiotika Peirce, seni Islam.

\begin{abstract}
Art is one of the elements of culture that has received special attention in Muslim society. From a religious perspective, one of the practices of art that is related to moral movement is seen on the da'wa visual media. This article aims to reveal the meaning of da'wa posters, what message designers want to convey to Muslims at large. In addition, it also seeks to find a connection between art and religion. It uses a qualitative method, whereas Peirce's semiotics is used as an analytical tool. The result shows that da'wa posters as a medium for preaching are an expression of love for the Creator. Da'wa posters are a form of persuasive media that reminds creatures' main duty to God, namely worship.
\end{abstract}

Keywords: visual da'wa, da'wa posters, Peirce's semiotics, Islamic art.

Correspondence author: Ahmad Faiz Muntazori, faiz.muntazori@gmail.com, Jakarta, Indonesia

This work is licensed under a CC-BY-NC 


\section{PENDAHULUAN}

Islam diyakini sebagai agama universal yang merupakan rahmat bagi semesta alam. Adalah tugas hakiki manusia, sebagai khalifah di muka bumi, untuk beribadah kepada Sang Pencipta. Dalam hal ini, adalah tugas semua Muslim pula untuk menyampaikan pesan bahwa Islam adalah agama yang damai dan penuh kasih sayang.

Islam sebagai agama dan juga pedoman hidup bagi penganutnya memiliki $\mathrm{Al}$ Quran, Hadis dan ijma (kesepakatan ulama) yang mengatur segala hal terkait seluruh aktivitas manusia, agar manusia dapat mengetahui batasan-batasan yang tidak boleh dilanggar dalam aktivitas kehidupan sehari-harinya. Umat Islam memahami dengan baik bahwa Islam tidak hanya mengatur dimensi vertikal, yaitu hubungan makhluk dengan Sang Pencipta. Islam juga mengatur dimensi horizontal, yaitu hubungan sesama makhluk, hubungan dengan alam, dan hubungan Islam dengan kebudayaan. H. A. R. Gibb (dalam Anshari 62) menyatakan bahwa Islam itu lebih dari sekadar sistem teologi, karena mencakup pula unsur kebudayaan yang sempurna. Gazalba (13) juga menyatakan bahwa Islam bukan sekadar agama (ibadah mahdah), tetapi pula mencakup kebudayaan.

Oleh karena itu, semua unsur kebudayaan, sebagaimana dirumuskan oleh Koentjaraningrat - meliputi (1) sistem dan organisasi kemasyarakatan; (2) sistem religi dan upacara keagamaan; (3) sistem mata pencaharian; (4) sistem (ilmu) pengetahuan; (5) sistem teknologi dan peralatan; (6) bahasa; dan (7) kesenian-telah diatur dalam Islam. Namun, dalam tulisan ini penulis hanya akan berfokus pada unsur kesenian, yang mendapat perhatian khusus dalam kebudayaan masyarakat Islam.

Menurut Gazalba (299) seni atau kesenian adalah manifestasi dari budaya manusia yang memenuhi syarat estetika. Inti dari seni adalah usaha menciptakan bentuk-bentuk yang menyenangkan (indah), baik dalam bidang seni sastra, seni musik, seni tari, seni rupa, maupun seni drama. Rizali (2) menyatakan bahwa sebagai salah satu unsur kebudayaan, seni merupakan fitrah manusia yang dianugerahkan Allah SWT untuk suatu kegiatan yang melibatkan kemampuan kreatif dalam mengungkapkan keindahan, kebenaran, dan kebaikan.

Penulis memfokuskan kajian penelitian ini pada karya seni rupa, sebagai salah satu bidang kesenian Islam yang mengalami perkembangan pesat. Hal ini dapat dilihat dari bangunan masjid yang semakin indah dan beragam bentuknya, bentuk karya visual seperti seni kaligrafi, poster, dan lain sebagainya. Al-Qardhawi (147) menjelaskan bahwa kesenian Islam, khususnya seni rupa, tampak dalam bentuk ornamen-ornamen yang mencerminkan keindahan pikiran seniman Muslim dan keterampilan goresan tangannya. Hasil karya seni itu dapat dilihat dengan jelas di masjid-masjid, kitab-kitab, istana-istana, gedung-gedung, dan lain-lain; seperti pada tembok dan langit-langit, pintu dan jendela; kadang juga di lantai-lantai, bagianbagian gedung, perabot-perabot rumah, barang-barang berharga, permadani, kain, dan pedang; juga pada berbagai material yang sering dipergunakan berupa batu, marmer, kayu, sutera, kulit, kaca, kertas, besi, tembaga, dan bermacam-macam barang tambang lainnya.

Dewi (207) mengungkapkan bahwa seni membuat perenungan tentang dunia material dan manusia untuk melihat adanya kenyataan lain yang belum pernah dilihat 
manusia. Seni menjadi medium antara dunia material dan kerohanian yang kekal. Seni adalah sesuatu yang memuat hal-hal yang transendental, membuat sesuatu yang tidak kita kenal sebelumnya menjadi nyata dan dapat kita pahami.

Proses-proses kesenian dalam perspektif agama memiliki esensi dan substansi yang saling berhubungan dengan khazanah gerakan moral, ikhtiar kesalehan individu dan sosial, maupun pencerdasan dan pembangunan bangsa. Nilai-nilai keluhuran, karakter, simbol-simbol keagamaan dan estetika alternatifnya, dapat dialihkan secara kreatif ke dalam otonomi ruang pribadi maupun ruang publik dan negara. Dengan demikian, dimensi keagamaan baik yang bersifat individual maupun sosial dapat berhubungan secara progresif dalam berbagai aksi kebudayaan. Keberadaan agama menjadi lebih leluasa untuk dihikmahi dan dihayati sebagai pencerah akal budi manusia di luar institusi, ibadah, ritualisme, sakramenta, dan upacara (Salad 16-17).

Praktik kesenian dalam perspektif agama yang berhubungan dengan gerakan moral, salah satunya tampak pada poster dakwah-media dakwah dengan konten keIslaman yang dibuat dalam bentuk poster. Struktur visual terdiri atas teks, imaji, dan mandatori. Teksnya berupa intisari atau kalimat utuh dari ayat Al Quran, Hadis, atau perkataan ulama. Imaji berupa gambar atau foto sebagai pendukung teks. Mandatori berupa logo dan akun Instagram kreator atau komunitas sebagai identitas.

Poster dakwah ini marak digunakan oleh para desainer Muslim sebagai cara mereka dalam berdakwah, karena diyakini bahwa dakwah merupakan salah satu kewajiban sebagai seorang Muslim. Berdakwah menggunakan media visual bukan hal yang baru, namun fenomena ini menjadi marak beberapa tahun ini. Hal ini berbanding lurus dengan perkembangan internet yang pesat, sehingga poster dakwah dapat disebarkan dengan mudah, khususnya melalui media sosial seperti Facebook, Instagram, dan Twitter. Media visual dianggap efektif untuk menyampaikan dakwah karena manusia secara alamiah lebih mudah mengingat pesan yang disampaikan secara visual. Sebagai makhluk simbolik, manusia memiliki kapasitas dan aktivitas pembuatan simbol yang universal, yang menemukan ekspresi dalam berbagai 'bentuk simbolik' seperti seni, agama, hukum, politik, dan ekonomi (Erll 6).

Narasi keseimbangan dan keselarasan bentuk seni dalam Islam, sebagaimana yang disyariatkan oleh Al Quran, bukanlah semata proses kreatif penyeimbangan kriteria seni dan kriteria dakwah, melainkan juga proses holistikasi antara religiusitas, etika, dan estetika. Seni dapat dirujuk sebagai kekuatan psikologis yang mampu menembus dinding rohani secara lebih intensif melalui transendensi kode-kode simbolik dan estetik (

Poster dakwah sarat dengan nilai-nilai ajaran agama Islam sebagai konten utamanya, namun sebagai sebuah karya desain perlu juga memperhatikan penggunaan elemen dan prinsip desain. Karya visual yang baik akan menarik perhatian audiens, sehingga memperbesar peluang pesan dakwahnya diterima dengan baik. Hubungan agama dan estetika ini yang akan menjadi fokus utama dalam tulisan ini.

Tulisan ini ingin mengungkapkan makna poster dakwah dan pesan apa yang ingin disampaikan oleh desainer kepada umat Islam secara luas. Selain itu, juga ingin memahami hubungan antara seni dan agama - apakah poster dakwah menggunakan agama sebagai konten dan berpengaruh kuat terhadap karya seni yang dibuatnya, atau agama hanya dijadikan sebagai pelengkap dalam poster dakwah? 


\section{METODE}

Penelitian ini merupakan penelitian kualitatif. Data disajikan dalam bentuk narasi dan gambar, bukan dalam bentuk angka. Data primer diperoleh dari media dakwah dalam bentuk visual, sedangkan data sekunder diambil dari hasil penelitian, jurnal ilmiah, dan buku teks yang secara langsung maupun tidak langsung berkaitan dengan objek penelitian.

Analisis data dilakukan dengan menggunakan semiotika Peirce, yakni dengan dengan mengungkap penanda-penanda visual dalam poster dakwah visual. Hasil analisis data kemudian disajikan dalam bentuk formal dan informal. Secara formal, analisis data disajikan dalam bentuk gambar-gambar dua dimensi yang disertai keterangan. Secara informal, analisis data disajikan melalui kata-kata, kalimat, dan bentuk-bentuk narasi yang lain.

Peirce melihat tanda dalam satu mata rantai tanda yang tumbuh, dijabarkan dalam bentuk tripihak (triadic). Dalam hal ini, setiap gejala secara fenomenologis mencakup 1) bagaimana sesuatu menggejala tanpa harus mengacu pada sesuatu yang lain (qualisigns, firstness, in-itselfness), 2) bagaimana hubungan gejala tersebut dengan realitas di luar dirinya yang hadir dalam ruang dan waktu (sinsigns, secondness/ overagaintsness), dan 3) bagaimana gejala tersebut dimediasi, direpresentasi, dikomunikasikan, dan "ditandai" (legisigns, thirdness/in-betweenness).

Ketiga kategori di atas menunjukkan bahwa realitas hadir dalam tiga kemungkinan. Cara Peirce melihat "realitas" dalam tiga kemungkinan itu sangat penting untuk memahami jargon-jargon lainnya. Dari situlah kemudian dihasilkan tiga trikotomi: trikotomi pertama adalah qualisign, sinsign, dan legisign; trikotomi kedua adalah ikonis, indeks, dan simbol; trikotomi ketiga adalah term (rheme), proposisi (dicent), dan argumen. Relasi itu dapat digambarkan sebagai berikut:

\begin{tabular}{|l|l|l|l|}
\hline & $\begin{array}{l}\text { Relasi dengan } \\
\text { Representamen }\end{array}$ & $\begin{array}{l}\text { Relasi dengan } \\
\text { Objek }\end{array}$ & Relasi dengan Interpretan \\
\hline $\begin{array}{l}\text { Kepertamaan } \\
\text { (firstness) }\end{array}$ & $\begin{array}{l}\text { Bersifat potensial } \\
\text { (qualisign) }\end{array}$ & $\begin{array}{l}\text { Berdasarkan } \\
\text { keserupaan } \\
\text { (ikonis) }\end{array}$ & Terms (rheme) \\
\hline $\begin{array}{l}\text { Keduaan } \\
\text { (secondness) }\end{array}$ & $\begin{array}{l}\text { Bersifat } \\
\text { keterkaitan } \\
\text { (sinsign) }\end{array}$ & $\begin{array}{l}\text { Berdasarkan } \\
\text { penunjukkan } \\
\text { (indeks) }\end{array}$ & $\begin{array}{l}\text { Suatu pernyataan yang } \\
\text { bisa benar bisa salah } \\
\text { (proposisi atau dicent) }\end{array}$ \\
\hline $\begin{array}{l}\text { Ketigaan } \\
\text { (thirdness) }\end{array}$ & $\begin{array}{l}\text { Bersifat } \\
\text { kesepakatan } \\
\text { (legisign) }\end{array}$ & $\begin{array}{l}\text { Berdasarkan } \\
\text { kesepakatan } \\
\text { (simbol) }\end{array}$ & $\begin{array}{l}\text { Hubungan proposisi yang } \\
\text { dikenal dalam bentuk } \\
\text { logika tertentu (internal) } \\
\text { (argumen) }\end{array}$ \\
\hline
\end{tabular}

Tabel 1. Klasifikasi Sepuluh Tanda yang Utama dari Peirce (Christomy 116; Nöth 45)

Peirce dalam Danesi (32) menyebut tanda sebagai representamen dan konsep, benda, gagasan, dan seterusnya, yang diacunya sebagai objek. Makna (impresi, kogitasi, perasaan, dan seterusnya) yang diperoleh dari sebuah tanda diberi istilah interpretan. Dengan kata lain, sebuah tanda senantiasa memiliki tiga dimensi yang saling terkait: Representamen (R), sesuatu yang dapat dipersepsi (perceptible); Objek 
(O), sesuatu mengacu kepada hal lain (referential); dan Interpretan (I), sesuatu yang dapat diinterpretasi (interpretable) (Christomy 117).

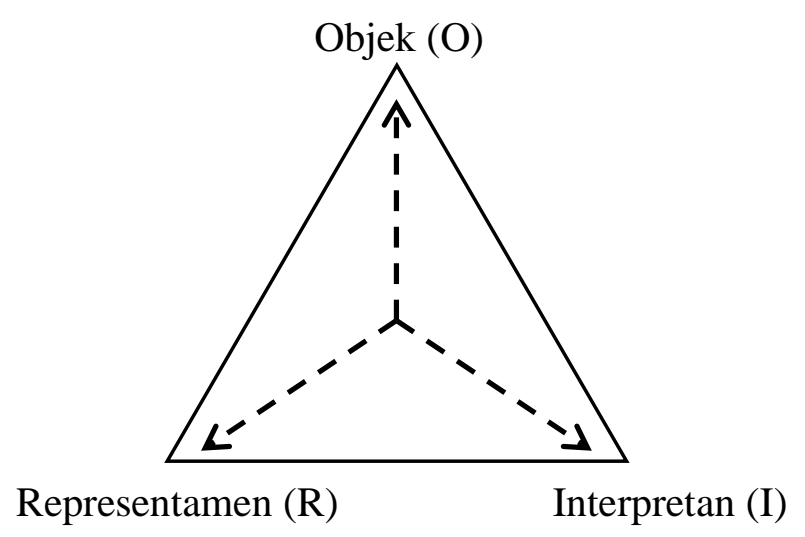

Gambar 1. Tiga Dimensi Tanda

(Christomy 117)

Peirce memperkenalkan istilah semiosis untuk menamai "aktivitas dari tanda" (the activity of sign) (Pietro dalam Christomy 129). Semiosis yang saling terkait dan mapan dapat dilihat sebagai sebuah wujud kebudayaan. Zoest (50) menjelaskan bahwa perbedaan semiosis menjadi pembeda antara dua kebudayaan. Ketika mengkaji sebuah semiosis tertentu di dalam masyarakat, pada dasarnya kita tengah menggali sebuah ideologi yang memungkinkan penggunaan tanda-tanda tertentu. Menurut Zoest (53), barang siapa mempelajari ideologi harus memperhatikan keteranganketerangan budaya-“ideologi mengarahkan budaya." Dengan demikian, semiotika membantu kita untuk menggali asumsi-asumsi mendasar (ideologi) dari sebuah ekspresi.

Peirce melihat proses semiosis dalam kerangka logika. Ketiga dimensi tanda di atas, Representamen, Objek, dan Interpretan, dikombinasikan dengan tanda lain sehingga menghasilkan 27 kategori tanda. Sepuluh tanda di antaranya sangat penting dan realistis. Kesepuluh kategori tanda tersebut dapat diklasifikasikan berdasarkan konsep tiga pandangan Peirce tentang realitas: 1) potensialitas (firstness), 2) aktualitas (secondness), 3) regulasi (thirdness). Kemudian, kesepuluh tanda tersebut dibagi dua kelompok keterkaitan berdasarkan 1) kemungkinan (hipotesis/abduksi), dan 2) keterkaitan secara induktif dan deduktif (non-abduksi). Colapietro dalam Christomy (131) menyebutkan, deduksi "menyepakati" bahwa sesuatu adalah kasus yang seharusnya; induksi "menunjukkan" bahwa sesuatu itu kenyatannya demikian, dan abduksi menggambarkan sesuatu yang mungkin. Berikut ini kombinasi semiosis yang mendasar: 1) abduksi, 2) induksi, dan 3) deduksi

1. Abduksi dan Induksi

a. Term $\rightarrow$ ikonik $\rightarrow$ qualisign

b. Term $\rightarrow$ ikonik $\rightarrow$ sinsign

c. Term $\rightarrow$ ikonik $\rightarrow$ legisign

d. Term $\rightarrow$ indeksikal $\rightarrow$ qualisign

e. Term $\rightarrow$ indeksikal $\rightarrow$ sinsign

f. Term $\rightarrow$ indeksikal $\rightarrow$ legisign; term $\rightarrow$ simbolik $\rightarrow$ legisign 
2. Deduksi

g. Proposisi $\rightarrow$ indeksikal $\rightarrow$ sinsign

h. Proposisi $\rightarrow$ indeksikal $\rightarrow$ legisign

i. Proposisi $\rightarrow$ simbolik $\rightarrow$ legisign

j. Argumen $\rightarrow$ indeksikal $\rightarrow$ legisign

\section{HASIL DAN PEMBAHASAN}

\section{Poster Dakwah}

Secara umum pengertian kesenian Islam adalah segala hasil usaha dan daya upaya, buah pikiran dari kaum Muslim untuk menghasilkan sesuatu yang indah. Seni Islam dapat juga diberi batasan sebagai suatu seni yang dihasilkan oleh seniman atau desainer Muslim; atau dapat juga berupa seni yang sesuai dengan apa yang dibayangkan oleh seorang Muslim (Situmorang 9). Dalam hal ini, setiap keindahan yang dihasilkan oleh seniman Muslim hendaklah menggambarkan sikap pengabdian kepada ajaran atau petunjuk agama Islam-dengan kata lain, Islami, sesuai dengan pandangan hidup seorang Muslim

Seni Islam merupakan hasil dari pengejawantahan Keesaan pada bidang keanekaragaman. Ia merefleksikan kandungan prinsip Keesaan Ilahi, kebergantungan seluruh keanekaragaman kepada Yang Esa, kesementaraan dunia dan kualitas-kualitas positif dari eksistensi kosmos atau makhluk (Nasr 18). Menurut Burckhardt dalam Nasr (18) seni Islam diilhami oleh spiritualitas Islam secara langsung, sedangkan wujudnya dibentuk oleh karakteristik-karakteristik tertentu dari tempat penerima wahyu Al Quran, yaitu dunia Semit dan nomadis yang nilai-nilai positifnya diuniversalkan Islam.

Hasil perwujudan seni Islam dibentuk oleh karakteristik tertentu, di antaranya estetika dan kreativitas. Menurut penilaian Islam, segala bentuk seni selain merupakan karya ibadah (pengabdian kepada Allah), juga mengandung dan mengungkapkan keindahan (Rizali 4). Seni Islam juga mengandung kreativitas, yang berkaitain erat dengan estetika dan sangat tergantung pada kesadaran pribadi seniman. Estetika dan kreativitas merupakan syarat mutlak sebuah karya seni. Namun bagi seorang seniman Muslim, berkarya bukan sekadar mencipta karya seni yang bermanfaat dan indah, melainkan sekaligus menjalankan ibadahnya (Rizali 6). Yusuf Al-Qardhawi berpandangan bahwa estetika (seni) Islami merupakan kebutuhan rasa (intuisi) yang dapat meningkatkan derajat dan kemuliaan manusia, bukan seni yang dapat menjerumuskan manusia ke dalam kehinaan (Yunus et al. 41). Herawati (160) menyatakan bahwa keindahan dilihat manifestasinya dalam karya seni, maka seni Islam, bentuk dan aspeknya berorientasi pada tauhid, yaitu pengesaan Tuhan di satu sisi dan pengosongan diri di sisi lain.

Salah satu manifestasi seni Islam di era sekarang ini adalah media dakwah dalam bentuk visual - sebagian kelompok menyebutnya sebagai dakwah komunikasi visual. Ni'mah (109) mengartikan dakwah komunikasi visual sebagai aktivitas yang dilakukan untuk menyampaikan informasi atau pesan yang mengajak untuk berbuat amar ma'ruf nahi mungkar sesuai dengan pedoman dalam Al Quran dan as-Sunnah, dengan memanfaatkan media komunikasi visual. Media komunikasi visual yang digunakan seperti iklan, poster, baliho, dan lain-lain. 
Pada penelitian ini, media dakwah visual yang dibahas berupa poster dakwah yang mengajak berbuat kebajikan dan mencegah kemungkaran melalui kalimat dan ilustrasi yang bernuansa Islami, seperti kata-kata, kalimat, ataupun gambar yang bersumber pada Al Quran dan Hadis. Selain itu, juga dapat menggunakan kata-kata mutiara atau kalimat hasil pemikiran para tokoh Islam (Ni'mah 110). Adapun menurut Zuafa (31) poster dakwah mengandung unsur kreatif, dinamis, dan estetis, serta menggunakan diksi dan gaya bahasa yang bernuansa dakwah Islam.

Media sosial dan dakwah visual memberdayakan kaum muda Muslim yang tidak memiliki pendidikan agama formal dan kuat untuk terlibat dalam kegiatan dakwah. Semua orang bisa menjadi pengkhotbah, jika dia mengelola keterampilan visual dan strategi komunikasi tertentu. Dakwah visual dan persuasi Islami menyenangkan namun radikal, penuh warna namun konservatif, sederhana namun keras, interaktif namun dogmatis (타 76).

\section{Analisis Struktur Visual Poster Dakwah}

Struktur visual poster dakwah pada linimasa Instagram terdiri atas beberapa elemen desain seperti poster pada umumnya, yaitu visual, teks, dan mandatori. Imaji dapat berupa foto dan gambar. Misalnya, foto manusia, alam, lingkungan, benda, dan lain sebagainya. Objek gambar hampir sama dengan foto; perbedaannya, gambar manusia ada yang digambarkan secara realis dan tanpa wajah (faceless). Imaji adalah salah satu elemen utama poster dakwah yang menjadi bagian dari keseluruhan konsep desain dan pesan yang ingin disampaikan. Elemen lain adalah rupa dan bentuk (shape $\mathcal{E}$ form), biasanya merupakan bangunan, benda-benda, tekstur, dan lain sebagainya. Warna adalah elemen pendukung untuk menjadikan karya desain lebih menarik, dapat berupa warna alam, warna yang ada pada rupa dan bentuk (shape $\mathcal{E}$ form), atau warna yang memang sengaja digunakan dalam desain poster.

Teks berupa tajuk (headline), anak tajuk (subheadline), dan bodycopy. Tajuk adalah teks utama yang merepresentasikan pesan pada sebuah poster. Dalam poster dakwah, tajuk biasanya berupa kutipan sederhana yang merupakan intisari atau potongan dari ayat Al Quran, Hadis, maupun perkataan ulama. Anak tajuk umumnya merupakan kalimat tambahan yang memperjelas tajuk, sedangkan bodycopy biasanya berupa kalimat utuh ayat Al Quran, Hadis, atau perkataan ulama yang dijadikan dasar untuk pembuatan tajuk.

Mandatori dalam poster dakwah berupa logo dan akun Instagram. Logo dapat berupa identitas komunitas desainer Muslim, kelompok pengajian, organisasi, LSM, atau lainnya. Akun Instagram dapat berupa akun kreator atau akun komunitas yang digunakan untuk mengunggah, membagikan, dan menyebarkan poster dakwah tersebut. Struktur visual poster dakwah secara ringkas dapat dilihat pada tabel berikut:

\begin{tabular}{|c|c|c|}
\hline No & Elemen Desain & Elemen Desain Poster Dakwah \\
\hline \multicolumn{3}{|c|}{ Visual } \\
\hline 1 & Imaji & $\begin{array}{l}\text { Foto atau gambar manusia, lingkungan, alam dan } \\
\text { lainnya }\end{array}$ \\
\hline 2 & $\begin{array}{l}\text { Rupa dan Bentuk } \\
\text { (Shape \& Form) }\end{array}$ & $\begin{array}{l}\text { Bangunan sekitar, objek pendukung, garis, tekstur, dan } \\
\text { lainnya. }\end{array}$ \\
\hline 3 & Warna & $\begin{array}{l}\text { Warna pada rupa dan bentuk atau yang sengaja dibuat } \\
\text { dalam desain. }\end{array}$ \\
\hline
\end{tabular}




\begin{tabular}{|c|l|l|}
\hline \multicolumn{2}{|l|}{ Teks } & $\begin{array}{l}\text { Kutipan yang merupakan intisari dari ayat Al Quran, } \\
\text { Hadis, atau perkataan ulama yang dijadikan sebagai } \\
\text { tema pesan pada setiap poster dakwah }\end{array}$ \\
\hline 1 & Tajuk & Kalimat pendukung untuk memperkuat tajuk. \\
\hline 3 & Bodycopy & $\begin{array}{l}\text { Kalimat redaksi utuh ayat Al Quran, Hadis, atau } \\
\text { perkataan ulama yang intisarinya dijadikan sebagai } \\
\text { tajuk. }\end{array}$ \\
\hline \multicolumn{2}{|l|}{ Mandatori } & Logo komunitas desainer, kelompok pengajian \\
\hline 2 & Akun Instagram & $\begin{array}{l}\text { Nama akun pribadi kreator atau desainer atau akun } \\
\text { komunitas }\end{array}$ \\
\hline
\end{tabular}

Tabel 1. Struktur Visual Poster Dakwah Digital

Unsur atau elemen desain yang meliputi bentuk, raut, ukuran, arah, tekstur, warna, nilai (value), dan ruang pada poster dakwah merupakan penanda visual atau wujud minimal dari representasi visual (Danesi 86). Danesi memberikan sedikit penjelasan mengenai unsur atau elemen desain yang menjadi penanda visual:

'Penanda visual yang dirancang untuk menunjukkan bentuk garis luar dari sesuatu dikenal dengan nama bentuk. Segala sesuatu yang kita lihat dapat direpresentasikan melalui komposisi garis dan bentuk; misalnya, awan adalah bentuk, cakrawala adalah garis. Unsur-unsur lain termasuk nilai, warna dan tekstur. Nilai mengacu pada gelap atau terang dalam sebuah garis dan bentuk. Nilai memainkan peran penting dalam menggambarkan kontras antara gelap dan terang. Warna menyampaikan suasana, perasaan, atmosfir. Inilah mengapa kita berbicara tentang warna-warni yang "hangat, "lembut", "dingin", "keras". Seperti yang kita lihat di atas, warna secara konotatif memiliki nilai simbolis yang spesifik menurut budaya. Tekstur mengacu pada perasaan indera sentuhan yang digugah secara imajinistik saat kita melihat sebuah permukaan' (Danesi 87).

Penanda-penanda visual membangun sebuah sistem signifikasi yang menciptakan kepribadian bagi sebuah produk (Danesi 229). Oleh karena itu, menjadi penting bagi penulis mengidentifikasi setiap elemen desain pada poster dakwah untuk mengetahui representasi visualnya, selain juga untuk mempermudah dalam membangun konstruksi pemaknaan pada poster dakwah tersebut. 


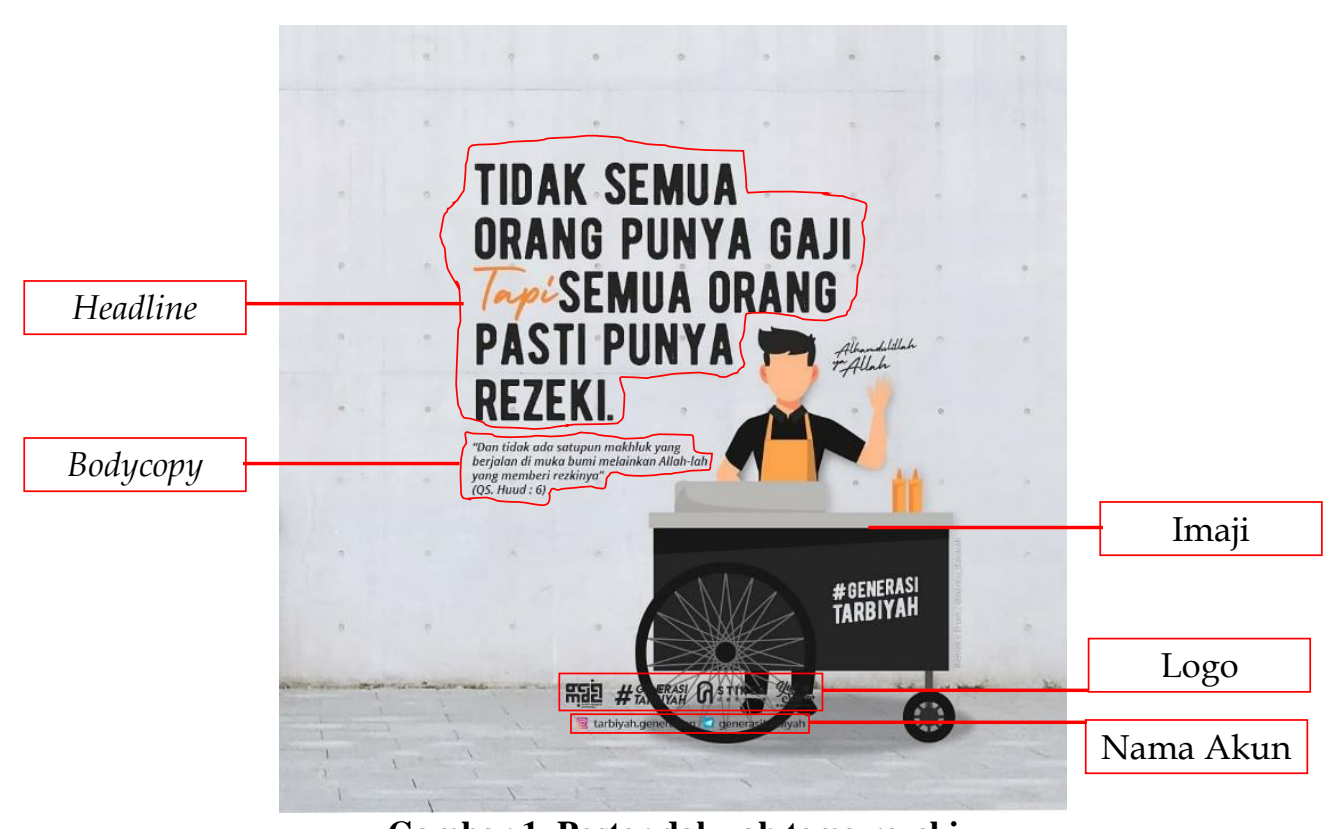

Gambar 1. Poster dakwah tema rezeki

( Sumber: @ tarbiyah.generation "Stiker Dakwah Edisi 78")

Pada Gambar 1, imaji berupa gambar seorang pedagang keliling yang membawa dagangannya. Desainer memahami bahwa menggambar makhluk hidup dilarang oleh syariat Islam, sehingga bagian wajah tidak digambarkan. Rupa dan bentuk divisualisasikan oleh dinding dan jalanan yang mendukung imaji dengan warna natural dinding dan jalan. Rupa dan bentuk, serta warna juga diperlihatkan pada pengaturan tata letak teks dan mandatori agar memikat mata.

Tajuk berupa kutipan "Tidak semua orang punya gaji tapi semua orang pasti punya rezeki." Ini merupakan transformasi dari ayat Al Quran yang dicantumkan sebagai bodycopy, yaitu Surat Huud ayat 6: "Dan tidak ada satu pun makhluk yang berjalan di muka bumi melainkan Allah-lah yang memberikan rezekinya."

Mandatori pada poster ini berupa logo dan akun Instagram. Terdapat empat buah logo di sana. Pertama, MDC yang merupakan singkatan dari Muslim Desainger Community-logo dalam bentuk huruf dan kaligrafi jenis kuffi. Kedua, \#GenerasiTarbiyah-menandakan bahwa logo ini dibuat oleh orang-orang yang tergabung dalam kelompok tarbiyah. Ketiga, stiker dakwah yang, sesuai dengan judul pada unggahan di Instagram, menerangkan bahwa ini adalah stiker dakwah nomor 78 . Keempat, logo Share Yuk - artinya, poster ini bebas untuk dibagikan ke siapa pun. Pada akun Instagram tertulis @tarbiyah.generation, sebagai nama akun milik komunitas tersebut. Selain akun Instagram juga dicantumkan akun Telegram, sebagai ajakan untuk bergabung ke dalam channel tersebut.

Mengacu pada semiosis yang dikembangkan oleh Peirce dalam membangun signifikasi sebuah tanda, maka penulis menggunakan model Proposisi -> Indeksikal -> Legisign untuk memaknai poster dakwah pada gambar 1. Penulis melihat poster sebagai satu kesatuan sistem penandaan, tidak diklasifikasikan berdasarkan teks, imaji, dan mandatori. Pada level penandaan yang pertama yaitu proposisi, penulis melihat teks dan imaji menyampaikan pesan yang merupakan intisari dari ayat Al Quran. Proposisi dalam semiotika menjelaskan bahwa pesan tersebut dapat diuji 
kebenarannya - jelas firman Allah dalam Al Quran adalah sesuatu yang benar tanpa ada keraguan di dalamnya. Diperkuat oleh imaji berupa gambar seorang pedagang makanan keliling yang rezekinya mengalir walaupun harus membanting. Didukung juga dengan mandatori berupa identitas komunitas yang terus melakukan upaya dakwah melalui media komunikasi visual ini.

Level berikutnya adalah indeksikal. Teks tajuk berupa kutipan yang diubah dari salah satu ayat suci Al Quran, yaitu Surat Huud ayat 6, sedangkan imaji berupa gambar mengacu pada pedagang keliling yang tidak memiliki gaji tetap namun tetap mendapatkan rezeki untuk menjalani kehidupannya sehari-hari. Imaji tidak berupa pedagang besar dengan toko megah, sehingga dapat menjadi pengingat bagi para pedagang kecil yang harus berkeliling dari kampung ke kampung.

Pada level ketiga, yaitu legisign, dapat dipahami bahwa ini merupakan representasi dari kehidupan masyarakat kita-banyak di antara mereka yang tidak memiliki gaji tetap, tidak ada jumlah pendapatan pasti setiap bulan, namun dengan bekerja apa pun mereka tetap mendapatkan rezekinya untuk menghidupi diri dan keluarganya. Mereka yakin akan rezeki yang Allah berikan, kendati harus berdagang dengan modal kecil dan keterampilan ala kadarnya, sebagaimana janji Allah dalam ayat Al Quran yang tertera pada poster dakwah tersebut.

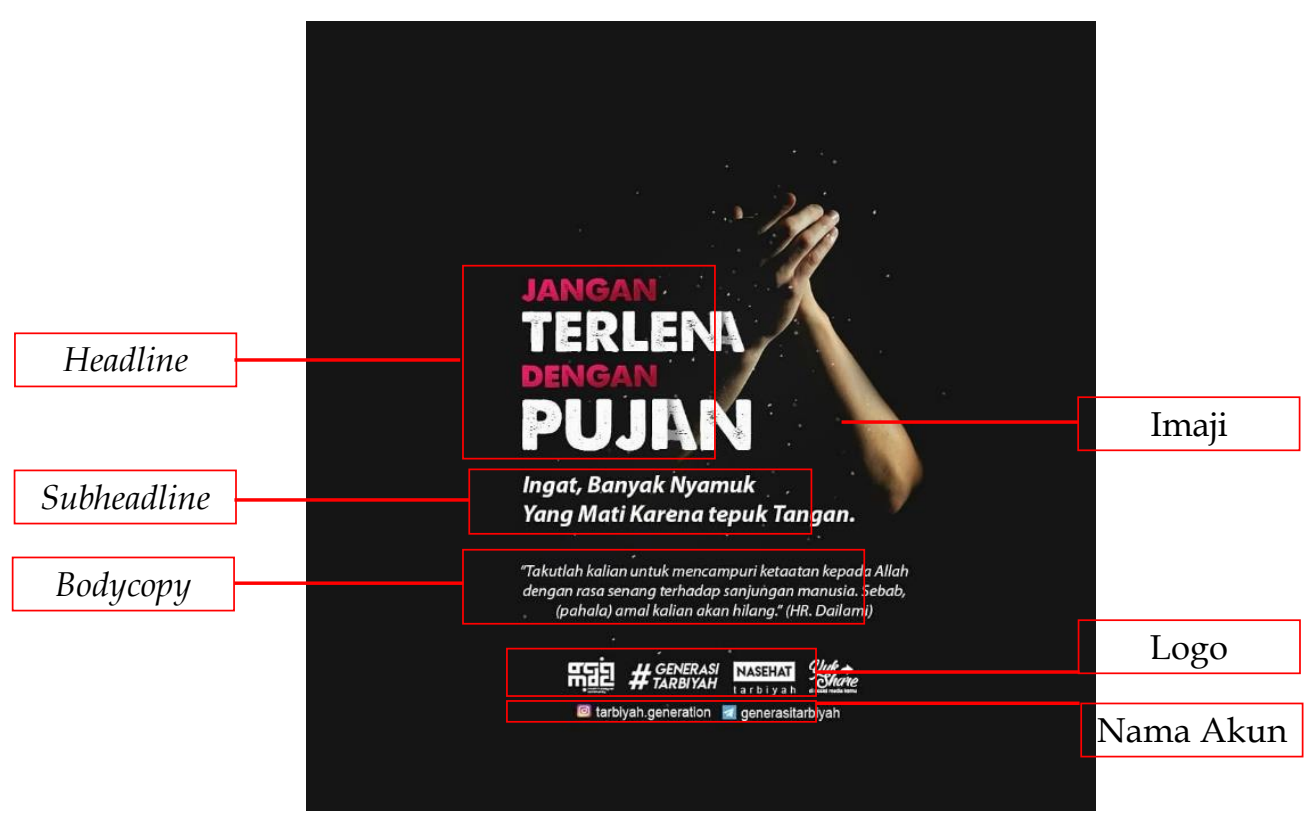

Gambar 2. Poster dakwah tema pujian

(Sumber: @ tarbiyah.generation "Nasehat Tarbiyah Edisi 197")

Poster pada Gambar 2 bertajuk "Jangan Terlena dengan Pujian," didukung oleh anak tajuk "Ingat, Banyak Nyamuk yang Mati karena Tepuk Tangan." Bodycopy berupa Hadis yang diacu oleh tajuk dan anak tajuk, yaitu "Takutlah kalian untuk mencampuri ketaatan kepada Allah dengan rasa senang terhadap sanjungan manusia. Sebab, (pahala) amal kalian akan hilang" (H.R. Dailami). Imaji berupa foto tangan yang sedang bertepuk, rupa dan bentuk serta warna nampak pada pengolahan teks dan mandatori serta latar belakang poster. Logo dan nama akun hampir sama dengan yang tertera pada Gambar 1, kecuali pada logo Nasehat Tarbiyah. Poster ini dibuat dan diunggah oleh akun yang 
sama, dengan penamaan yang berbeda. Judul teks pada unggahan Instagram ini adalah Nasehat Tarbiyah No. 197.

Sama halnya dengan poster sebelumnya, Gambar 2 juga menggunakan skema Proposisi -> Indeksikal -> Legisign. Level penandaan tingkat pertama pada proposisi, berupa sebuah peringatan tentang sanjungan dan pujian dari Nabi Muhammad SAW melalui sabda beliau dalam Hadis yang diacu pada poster tersebut. Mengenai ujian kebenaran pernyataan tersebut, tajuk mengutip Hadis yang tertera pada poster tersebut. Didukung oleh imaji berupa kedua tangan yang sedang bertepuk.

Pada level indeksikal, teks berupa konten yang mengacu pada sebuah Hadis Nabi Muhammad SAW. Adapun imaji berupa foto tangan yang sedang bertepuk, merujuk pada kebiasaan manusia ketika memberikan pujian dengan bertepuk tangan. Level berikutnya adalah legisign-poster pada Gambar 2 ini merupakan fenomena umum yang terjadi di kalangan masyarakat. Sanjungan, pujian yang diberikan terkadang membuat orang lupa diri dan menjadi sombong. Berlaku baik untuk masyarakat biasa maupun para pemuka agama.

Poster ini sebagai pengingat akan bahaya sanjungan dan pujian yang bisa membuat manusia khilaf dari ketaatan dan menjadi sombong. Sebuah nasihat dalam bentuk visual yang ditujukan untuk masyarakat Muslim secara luas. Bahkan aktif dalam kegiatan berdakwah pun tidak luput dari sanjungan dan pujian yang bisa membuat manusia lupa diri.

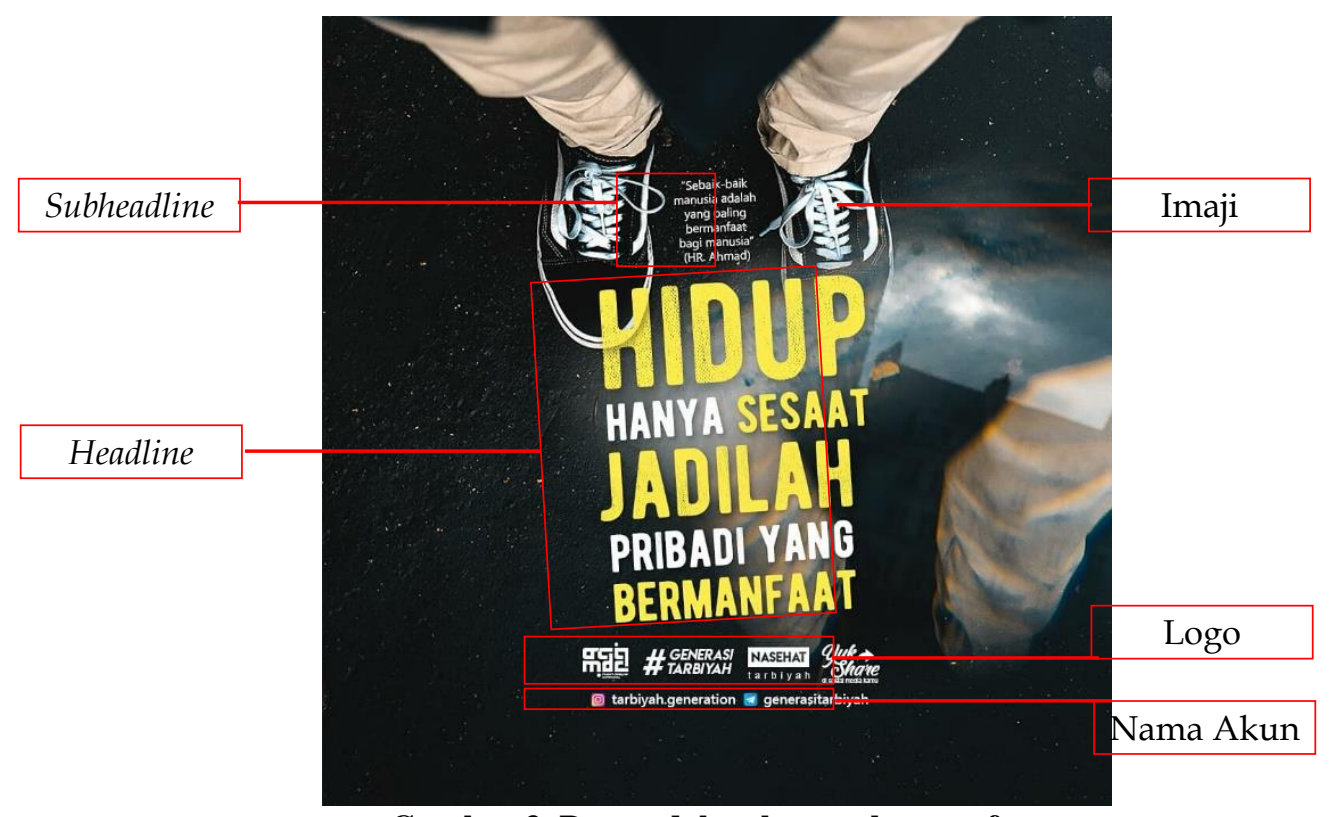

Gambar 3. Poster dakwah tema bermanfaat

(Sumber: @ tarbiyah.generation "Nasehat Tarbiyah Edisi 225")

Pada Gambar 3, tajuk bertuliskan "Hidup Sehat hanya Sesaat Jadilah Pribadi yang Bermanfaat," dengan bodycopy Hadis yang diacu oleh tajuk, yaitu "Sebaik-baik Manusia adalah yang paling bermanfaat bagi manusia yang lain" (H.R. Ahmad). Imaji berupa foto kaki manusia yang mengenakan sepatu dengan latar belakang kondisi langit yang cerah. Rupa dan bentuk, serta warna nampak pada pengolahan teks dan mandatori serta latar belakang poster. Mandatori sama persis dengan Gambar 2, 
karena dibuat dan diunggah oleh akun yang sama. Judul pada unggahan di akun Instagram yaitu Nasehat Tarbiyah No. 225.

Pada Gambar 3, pemaknaannya sama dengan dua bahasan sebelumnya, yaitu Proposisi -> Indeksikal -> Legisign. Sebuah proposisi ditampilkan dalam bentuk poster dengan pesan jadilah manusia yang bermanfaat, mengutip salah satu sabda Nabi Muhammad SAW yang tercantum dalam poster dakwah tersebut. Menjadi manusia bermanfaat digambarkan dengan dua kaki yang bersepatu-menyampaikan pesan bahwa orang yang bermanfaat adalah orang yang senang membantu orang lain dan ringan langkahnya dalam menawarkan bantuan kepada orang lain.

Indeksikal pada poster ini adalah tentang sesuatu yang diacu oleh elemenelemen visual dalam poster. Teks tajuk mengacu pada Hadis Nabi, dan gambarnya berupa foto kaki yang bersepatu. Kaki menunjukkan bahwa bermanfaat ditandai dengan ringannya langkah dalam membantu sesama. Pada tahap legisign, poster ini mengungkap fenomena yang berkembang di masyarakat di mana saat ini kepedulian antarsesama masih sangat minim, berat langkah kakinya dalam membantu orang lain. Poster ini mengingatkan akan pentingnya membantu orang lain agar menjadi manusia yang bermanfaat.

\section{Eksistensi dan Esensi Seni Islam dalam Poster Dakwah}

Poster dakwah merupakan karya seni yang tidak hanya mengutamakan pesan, namun juga memperhatikan nilai estetika. Pesan pada poster dakwah disampaikan melalui teks yang merupakan intisari dari ayat Al Quran dan Hadis, serta perkataan ulama atau pemikir Islam.

Penggunaan kalimat nash dalam poster dakwah adalah satu bentuk eksistensi penyampaian pesan yang dilakukan oleh desainer. Pesan-pesan kebaikan dan ajaran agama yang kerap muncul menjadi identitas poster dakwah, sehingga ketika muncul poster Islami tapi tidak mencantumkan ajaran-ajaran Islam, maka tidak bisa disebut sebagai poster dakwah.

Di samping pesan yang harus dapat diterima dan dipahami dengan baik, elemen desain pun menjadi perhatian. Penggunaan elemen-elemen desain disesuaikan dengan tema-tema bahasan yang mau dibuat dalam bentuk poster. Dengan demikian, poster dakwah ini memiliki nilai estetis yang tinggi.

Poster dakwah merupakan satu kesenian yang mengacu pada bentuk visual atau yang sering disebut bentuk perupaan, yang merupakan susunan atau komposisi atau satu kesatuan dari unsur-unsur rupa. Penyusunan unsur rupa dalam mewujudkan bentuk pada seni rupa memerlukan hukum atau asas penyusunan, untuk menghindari kemonotonan dan kekacau-balauan (Kartika 69).

Seni, dalam berbagai bentuknya, merupakan upaya manusia untuk menggambarkan dan mengekspresikan sesuatu yang ia rasakan dalam batinnya tentang berbagai realitas wujud, melalui pelbagai bentuk ekspresi yang indah, ilustratif, dan memiliki daya pengaruh yang kuat (Quthub 15).

Poster dakwah merupakan sebuah ekspresi kecintaan makhluk kepada Sang Khalik, dengan menciptakan sebuah karya yang mengutamakan nilai-nilai keindahan. Sebagaimana sebuah Hadis Nabi yang berbunyi "Sesungguhnya Allah itu indah dan mencintai keindahan." Ada sebuah pepatah Arab yang mengatakan bahwa "Mencintai apa yang dicintai oleh yang kita cintai, merupakan kesempurnaan cinta kita kepada yang kita cintai." 
Oleh karena itu, poster dakwah adalah sarana untuk menggapai kesempurnaan cinta kepada Sang Khalik. Cinta dalam bentuk menyampaikan wahyu-wahyu-Nya melalui ekspresi keindahan. Dapat dipahami bahwa pesan spiritual saja tidak cukup jika tidak diimbangi dengan karya yang indah.

Seni Islam mewujudkan, dalam taraf fisik yang secara langsung dapat dipahami oleh pikiran yang sehat, realitas-realitas dasar dan perbuatan-perbuatan, sebagai tangga bagi pendakian jiwa dari tingkat yang dapat dilihat dan didengar menuju ke Yang Gaib juga merupakan keheningan di atas setiap bunyi (Nasr 18). Seni Islam adalah sarana yang memungkinkan ruh Islam menembus segala macam dan bentuk aktivitas, merasuk ke seluruh kehidupan manusia untuk mengingatkannya akan kehadiran Tuhan ke mana pun dia melangkah pergi. Bagi orang yang senantiasa ingat kepada Allah, seni Islam selalu menjadi pendorong yang sangat bernilai bagi kehidupan spiritualnya dan sarana untuk merenungkan realitas Tuhan (Nasr 216).

Matta (22) menambahkan jika seni merupakan ekspresi estetika seseorang, maka materi dasar dari ekspresi estetika itu sesungguhnya terdapat pada persepsi dasar tentang berbagai realitas wujud: Tuhan, alam, manusia, dan kehidupan. Persepsi dasar itu adalah muatan-muatan kebenaran yang sesungguhnya merupakan substansi agama dan merupakan keyakinan-keyakinan awal yang senantiasa menyertai nurani manusia. Adapun rasa seni dan estetika merupakan respons emosional seseorang terhadap pengaruh yang ditimbulkan oleh realitas-realitas wujud dalam alam perasaannya. "Dalam wadah jiwa itulah, agama dan seni bertemu" (Quthub 5). Keduanya sama-sama menuju pada satu titik puncak: kesempurnaan.

\section{SIMPULAN}

Ekspresi seorang desainer dalam membuat sebuah karya seni merupakan salah satu bentuk kecintaan terhadap sesuatu. Ketika yang dibuat adalah sebuah media dakwah yang sifatnya adalah ajakan untuk mengingatkan sesama makhluk tentang keesaan Tuhan, maka ini adalah bentuk ekspresi kecintaan makhluk kepada Sang Khalik. Banyak cara yang dilakukan dalam mengekspresikan cinta, dan beragam pula bentuk kesenian yang dihasilkannya.

Menyampaikan ulang pesan-pesan ketuhanan dan kenabian dalam bentuk karya visual adalah salah satu upaya untuk menyentuh manusia agar dapat mudah menangkap dan memahami pesan Al Quran dan Hadis. Secara teori, pesan dalam bentuk visual dan simbolik dapat lebih mudah diterima dan ditangkap. Poster dakwah, sebagai media untuk berdakwah, merupakan salah satu ekspresi kecintaan kepada Sang Khalik. Media persuasif yang mengingatkan tugas utama makhluk kepada Tuhannya, yaitu beribadah.

\section{DAFTAR PUSTAKA}

@ tarbiyah.generation (Instagram). "Nasehat Tarbiyah Edisi 197. ." 2 Agustus 2019.

--- (Instagram). "Nasehat Tarbiyah Edisi 225. ." 10 Oktober 2019. 
101 | Human Narratives Vol.1, No.2, 2020, pp. 88-102

--- (Instagram). "Stiker Dakwah Edisi 78. ." 11 Oktober 2019.

Al-Qardhawi, Yusuf. Islam Dan Seni. Pustaka Hidayah, 2000.

Anshari, Endang Syaifuddin. Kuliah Al-Islam Pendidikan Agama Di Perguruan Tinggi. Rajawali Press, 1980.

Christomy, Tommy. "Peircean Dan Kajian Budaya." Semiotika Budaya, edited by Tommy Christomy and Untung Yuwono, Pusat Penelitian Kemasyarakatan dan Budaya Fakultas Ilmu Pengetahuan Budaya Universitas Indonesia, 2010.

Danesi, Marcel. Pesan, Tanda, Dan Makna: Buku Teks Dasar Mengenai Semiotika Dan Teori Komunikasi. translated by Evi Setyarini and Lusi Lian Piantari, Jalasutra, 2012.

Dewi, Ernita. "Seni Dan Pendekatan Diri Kepada Tuhan." SUBSTANTIA : Jurnal Ilmuilmu Ushuluddin dan Filsafat, vol. 12, no. 1, 2010, pp. 205-223, doi:http://dx.doi.org/10.22373/subtantia.v12i1.3787.

Erll, Astrid. "Travelling Memory." Parallax, vol. 17, no. 4, 2011, pp. 4-18, doi:https://doi.org/10.1080/13534645.2011.605570.

Gazalba, Sidi. Asas Kebudayaan Islam: Pembahasan Ilmu Dan Filsafat Tentang Ijtihad, Fiqh, Akhlak, Bidang-Bidang Kebudayaan, Masyarakat Dan Agama. Bulan Bintang, 1978.

Herawati, Andi. "Keindahan Sebagai Elemen Spiritual Perspektif Islam Tradisional." Jurnal Kawistara: Jurnal Ilmiah Sosial dan Humaniora, vol. 5, no. 2, 2015, doi:https://doi.org/10.22146/kawistara.7588.

Hew, Wai Weng. "The Art of Dakwah: Social Media, Visual Persuasion and the Islamist Propagation of Felix Siauw." Indonesia and the Malay World, vol. 46, no. 134, 2018, pp. 61-79, doi:https://doi.org/10.1080/13639811.2018.1416757.

Kartika, Dharsono Sony. Estetika. Rekayasa Sains, 2007.

Koentjaraningrat. Kebudayaan, Mentalitas Dan Pembangunan. Gramedia, 1974.

Matta, Muhammad Anis. "Seni Islam: Format Estetika Dan Muatan Nilai." Ruh Islam Dalam Budaya Bangsa : Konsep Estetika, edited by Aswab Mahasin et al., Yayasan Festival Istiqlal, 1996.

Nasr, Seyyed Hossein. Spiritualitas Dan Seni Islam. translated by Sutejo, Penerbit Mizan, 1994.

Ni'mah, Nilnan. "Dakwah Komunikasi Visual." Islamic Communication Journal, vol. 1, no. 1, 2016, http://dx.doi.org/10.21580/icj.2016.1.1.1241. 
Nöth, Winfried. Handbook of Semiotics. Indiana University Press, 1990.

Quthub, Muhammad. Manhajul Fannil Islam Daar El Syuruq, 1973.

Rizali, Nanang. "Kedudukan Seni Dalam Islam." Tsaqafa-Jurnal Kajian Seni Budaya Islam, vol. 1, no. 1, 2012, pp. 1-8.

Salad, Hamdy. Agama Seni: Refleksi Teologis Dalam Ruang Estetik. Yayasan Semesta, 2000.

Situmorang, Oloan. Seni Rupa Islam: Pertumbungan Dan Perkembangannya. Penerbit Angkasa, 1993.

Yunus, Pangeran Paita et al. "Unsur Estetika Islam Pada Seni Hias Istana Raja Bugis." Al-Ulum, vol. 12, no. 1, 2012, pp. 35-52, http://www.journal.iaingorontalo.ac.id/index.php/au/article/view/89.

Zoest, Art Van. Semiotika: Tentang Tanda, Cara Kerjanya Dan Apa Yang Kita Lakukan Dengannya. translated by Ani Soekowati, Yayasan Sumber Agung, 1993.

Zuafa, Nurma. "Karya Desain Grafis Sebagai Materi Dakwah (Studi Tentang Produk Desain Grafis Dan Materi Dakwah Dalam Grup "Muslim Designer Community" Di Facebook)." UIN Walisongo, 2016. 